\title{
RENEWABLE ENERGY RESOURCE APPLICATION: SOLAR THERMAL COOLING SYSTEMS IN INDONESIA
}

\author{
Melania Rahadiyanti \\ Department of Interior Architecture, Faculty of Creative Industry, \\ Universitas Ciputra, UC Town Citraland Surabaya 60219, INDONESIA \\ Email: melania.rahadiyanti@ciputra.ac.id
}

\begin{abstract}
The increasingly energy consumption needs for cooling space has caused utilization of solar thermal energy as a space cooler to become effort to decrease carbon emmision and air polution, and to save electricity power as well. This research aims to understand principle of solar thermal cooling system on building in Indonesia. This research uses literature review method by comparing some article from research journal about potencies and application of solar thermal cooling system on buildings in tropical country. The right utilization of solar thermal cooling system on building in Indonesia is solar thermal cooling system with open cycle with dust absorbent and humidity reduction.
\end{abstract}

Keywords: Humid tropical climate; solar thermal cooler; humidity reduction; dust absorbent.

\section{INTRODUCTION}

Energy consumption needs to air cooling especially in tropical area is getting higher, along with users desire to feel thermal comfortability in space where they have activity. This matter affects to increasing of cooling load in space (Haw, 2009). Based on data obtained from International Energy Agency (IEA), space heating and cooling system in comercial sector reached $40 \%$ from total energy consumption. Meanwhile in residential sector the amount was close to $70 \%$ (IEA, 2012).

In fact, there are so many renewable energy resources that can be used as fossil fuel subtitution, but many parties still do not utilize and develop it. Alternative energy like solar, wind, biomass, and seawave energy continuity can be expected, thus requiring so that it required calculation and consideration in use.

Due to the threat of global energy shortage, scientists increase more attention to solar energy in this recent years. So many technologies are available nowadays to catch and save solar energy to be used as water heater, cooker, room heater, power plants, foods dryer, and cooler (Ullah et al., 2013). In 2009, IEA reported that global needs to thermal energy showed $47 \%$ from total energy utilization, which was higher than total energy combination for electricity (17\%) and transportation (17\%) (IEA, 2012).

Based on those facts, cooling technology with solar thermal energy becomes center of attention in whole world. Energy crisis has opened door to solar energy to not only resolve high electricity needs, but also cooling needs (Ullah et al., 2013). The applica- tions of cooling include domestic refrigeration, comfort or space cooling in various sectors, industrial refrigeration and process cooling, cold storages with deep freezing, vaccine storages in PHCs, etc. (Singhal, 2014). Solar thermal energy utilization as alternative to cooling system expected becomes effort to reduce carbon emissions, reduce air pollution, and save electrical energy.

\section{Research Purpose}

This purpose of this research was to describe the principles of solar thermal cooling system in buildings, as effort to decrease carbon emmision and air pollution, also to save energy in Indonesia.

\section{Research Benefit}

The result of this research is expected to enrich knowledge in the application of solar thermal cooling system on building in Indonesia.

\section{METHODOLOGY}

Method used in this research is literature review, where the author first dug data and information about solar thermal cooling system on building from some articles and websites organized by organization working in the field of sustainable energy utilization, then did descriptive analysis by comparing some articles in research journal, especially research about potencies and application of solar thermal cooling system on building in tropical country. 


\section{Data Collection Method}

Data collection was done by finding journal and research article about solar thermal cooling system that has been disseminated in less than 10 years. The result of this research was adjusted with the location where this research was done, that is tropical climate area. These data were also supported with some guidance from online article or website, issued by renowned organization which care about global warming and energy saving.

\section{Data Analysis Method}

Data analysis was done by summarizing research result first about solar thermal cooling system in tropical climate area, and then by making comparison. This analysis generated description about the potencies of solar thermal system utilization in Indonesia, what system is appropriate and how is the proper application so that the cooling system is appropriate and can save energy in tropical climate area.

\section{THEORETICAL BASE}

Solar thermal cooling system is a technology system which uses solar thermal energy as the driving force energy to run termodynamic cycle in open or closed way in order to produce cold air (Marc et al., 2012). Figure 1 is example of solar thermal cooling systems manufactured by Austin Solar Air Conditioner.

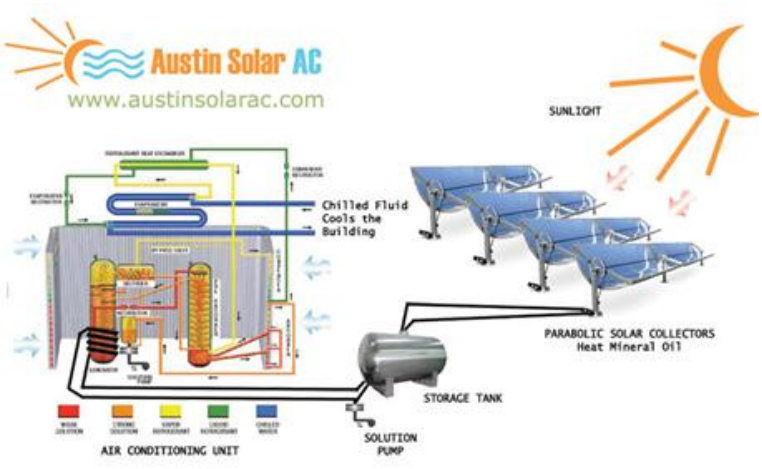

Fig. 1. Solar Thermal Cooling System Manufactured by Austin Solar Air Conditioner (http://www.austinsolarac. com/images/AC_Diagram_lg.jpg)

\section{Solar Thermal Cooling System Elements}

Generally, solar thermal cooling system consists of four main elements, they are (1) solar thermal collector tools, (2) thermal storage tank, (3) air condition controller tools, and (4) heat exchanger tools (Ullah et al., 2013).Function and type of each element of solar thermal cooling system are described as follow:

1. Solar thermal collector tools

Solar thermal collector receives light energy from sun and a rise in temperature, consequently cooling material in the emptying collector tube area that becomes hot through convection heat process (Ullah et al., 2013).

2. Thermal storage tank

Thermal storage tank functions to store cooling material which already heated by collector tube (Ullah et al., 2013).

3. Air condition controller tools

Air condition controller unit runs with cooling material which is already heated by thermal energy depositor tank, and that cooling material circulates through whole system (Ullah et al., 2013).

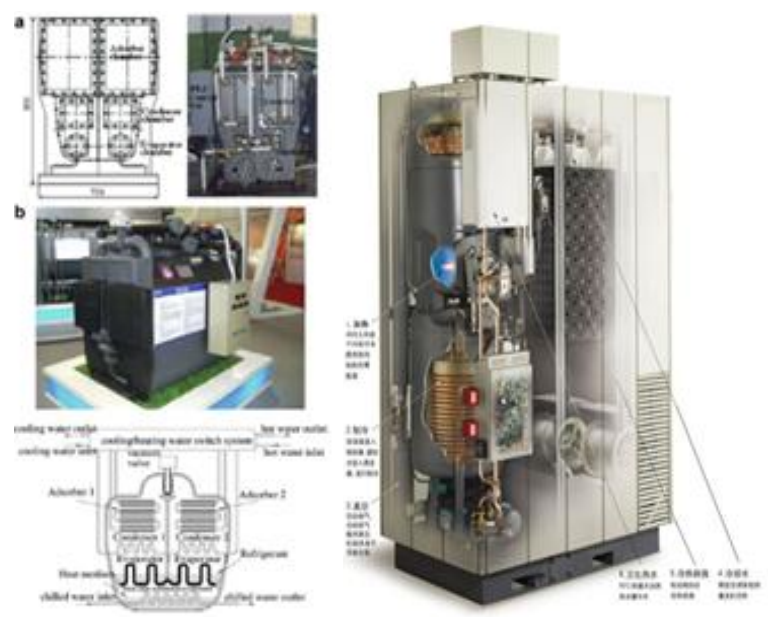

Fig. 2. Air Condition Controller Tools Type (http://www. hyne.cn/midhigh/sm_80.jpg)

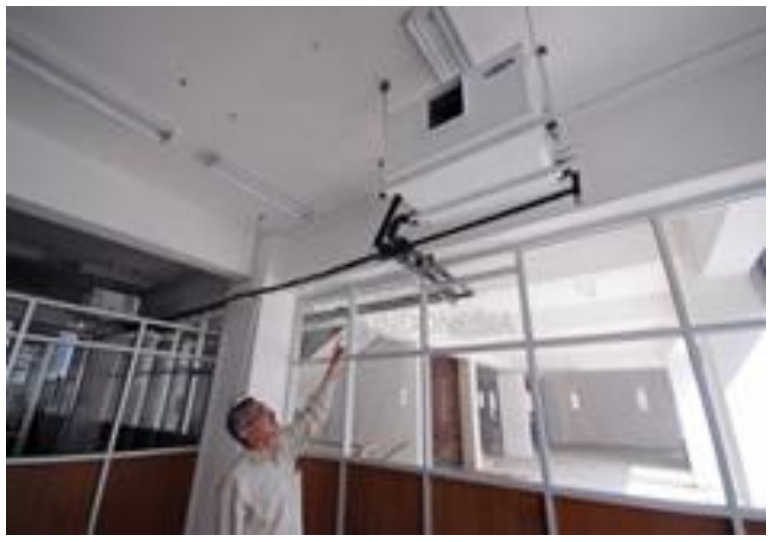

Fig. 3. Air Condition Controller Tools which Placed inside Object Space (http://news.metrotvnews.com/view/2014/ 04/17/231929/solar-thermal-cooling-system) 
Table 1. Type of Solar Thermal Collector Tools

\begin{tabular}{c|ccccc}
\hline Catcher Type & Solar air collector (SAC) & Flat-plate collector(FPC) & $\begin{array}{c}\text { Stationary parabolic compound } \\
\text { collector }(C P C)\end{array}$ \\
Vacuum tube collector (VTC)
\end{tabular}

Source: http://www.creativeenergyengineering.com/imacrea/solar_thermal_collectors_for_SAC.jpg

4. Heat exchanger tools

Heat exchanger is responsible to move heat between hot space to cool space (Ullah et al., 2013). In these machines the refrigerant in the form of liquid is mixed up in the absorbent which is separated out by using thermal heat in the form of vapour which is further condensed and expanded to get the desired temperature for a particular application. The refrigerant used in these machines depends on the requirement of temperature for a particular application. For example, the temperature requirement for space cooling is around ${ }^{18-26}{ }^{\circ} \mathrm{C}$, LiBr-Water combination is generally being used in vapour absorption machine. For applications where the temperature requirement are less to store perishable food products, generally between $-20{ }^{\circ} \mathrm{C}$ and $4{ }^{\circ} \mathrm{C}$, ammonia is being used as the refrigerant whose freezing temperature is much below the required temperature for cooling (Singhal, 2014).

\section{Cooler System Process with Solar Thermal Energy}

Cooler system which utilize energy from solar thermal is executed in a process that generally described furthermore. To utilize solar thermal in this system, solar thermal needs to be absorped on certain medium (usually in fluid form) by using solar collector, then this thermal energy is transfered to be used on generator. Medium to use can be in form of steam or hot water. Thermal (heat) owned by this medium is then given to generator using heat exchanger. This heat then becomes energy to run air cooler tools. Figure 4 shows process of solar thermal cooling system until it can make cool space.

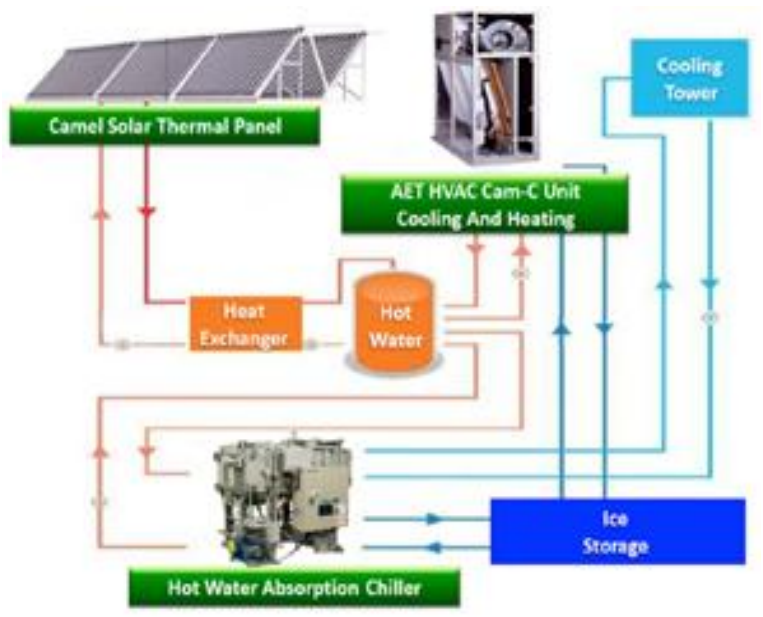

Fig. 4. Process Diagram of Solar Thermal Cooling System (http://www.camel-solar.com/cs/wp-content/uploads/2012/ 02/CS-1.jpg)

Solar thermal cooling system process can be distinguished into two types, namely closed cycle type and open cycle type, will be describe as follows:

1. Closed cycles, in which cooler system can be regulated as thermal energy absorbent to produce cool water so that it can be used on air cooler tools (air handling units, fan-coils, chilled beams, etc.). 
2. Open cycles, or called desiccant evaporative cooling systems, typically use water as cooling material and dessicant to directly used on air conditioning in ventilation system (IEA, 2012).

Figure 5 shows the comparison between cooling system with open cycle and closed cycle.

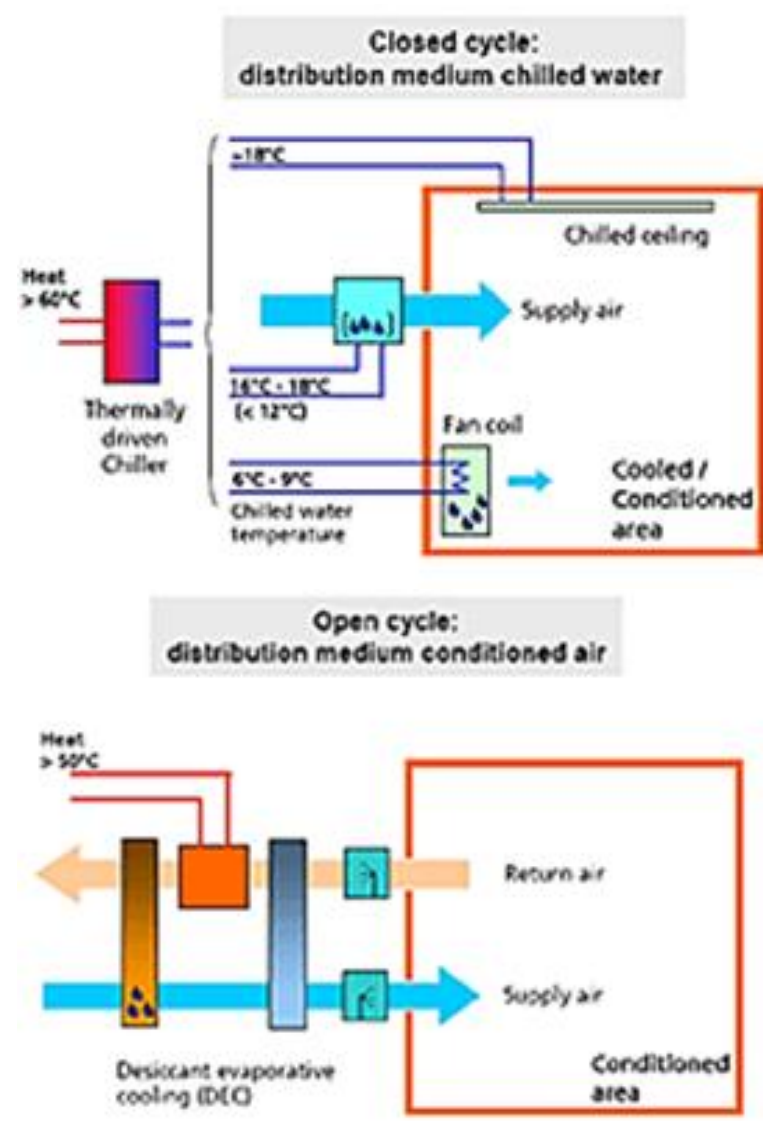

Fig. 5. The Comparison Between Cooling System with Open Cycle and Closed Cycle (http://www.solarserver. com/uploads/pics/verfahrensvergleich_en.gif)

For closed cycle, there are two types of absorping process: system based on adsorption and based on absorption. Based on closed cycle absorption, basic physical process is supported by technology which consists of minimum two chemical components, one of it acts as cooling material, and the other as absorbent. Efficiency from closed cycle system can be highly dependent to temperature of driver.

While closed cycle system produce cool water, which can be provided to some types of air conditioning tools, open cooling system produces conditioned air directly. Open cooling cycle control thermal energy is based on combination of evaporative cooling and decreasing of air humidity with dust absorbent (like hygroscopic, material which absorb humid steam).
Cooling system with dense dust absorbent is a mature comercial technology and looks to have penetrated to market in some areas (i.e. in some supermarkets in United States of America). Generally, cooling system with dust absorbent is a choice with centered ventilation system, offers ability to process air before entering space with conditioned air (Parmar, 2011).

Solar thermal air cooler with open cycle offers humidity controller as well as air conditioner. Beside that, solar thermal cooler, same as absorption cooler, not using cooling material (like CFC and HCFC which used in electricity pressurized cooler) which is dangerous greenhouse gases (IEA, 2012).

The humidity controller concept in open cycle solar thermal air cooler uses desiccant system. The basic idea is to use a material called a desiccant (in our case a type of salt called calcium chloride) to absorb water directly from the air without all the complicated machinery and energy requirements of conventional air conditioner. As the desiccant absorbs water, it becomes diluted and its ability to dry the air declines. The desiccant needs to be regenerated. This can be done by simply heating up the desiccant and letting the water evaporate to the outside air. Thus, the desiccant is concentrated and ready to return to its job of drying the indoor air (University of Maryland Solar Decathlon Team, 2007).

Generally, space cooling technology system process with solar thermal energy can be described in Table 2 as follows.

\section{RESULTS AND DISCUSSION}

\section{Benefits and Advantages of Using Solar Thermal Cooling System}

Solar thermal cooling system has some benefits and advantages. Advantages of using solar thermal cooling system as alternative solution on building in Indonesia are described as follows: (Reichardt, 2010; Ullah et al., 2013).

a. Cooling system uses renewable energy source. It can decrease electricity needs peak load related to conventional cooling system, where cooling is needed when maximum solar radiation happens.

b. Solar thermal cooling system can also operate in night by using deposit.

c. Hot water which created only needs small capacity container.

d. Does not create polution because does not need fossil fuel.

e. Free from carbon emission (Reichardt, 2010), except for production and transportation. Distribution is easy because production can be done in area which needs this equipment. 
Table 2. Comparison Between Cooling System with Open Cycle and Closed Cycle

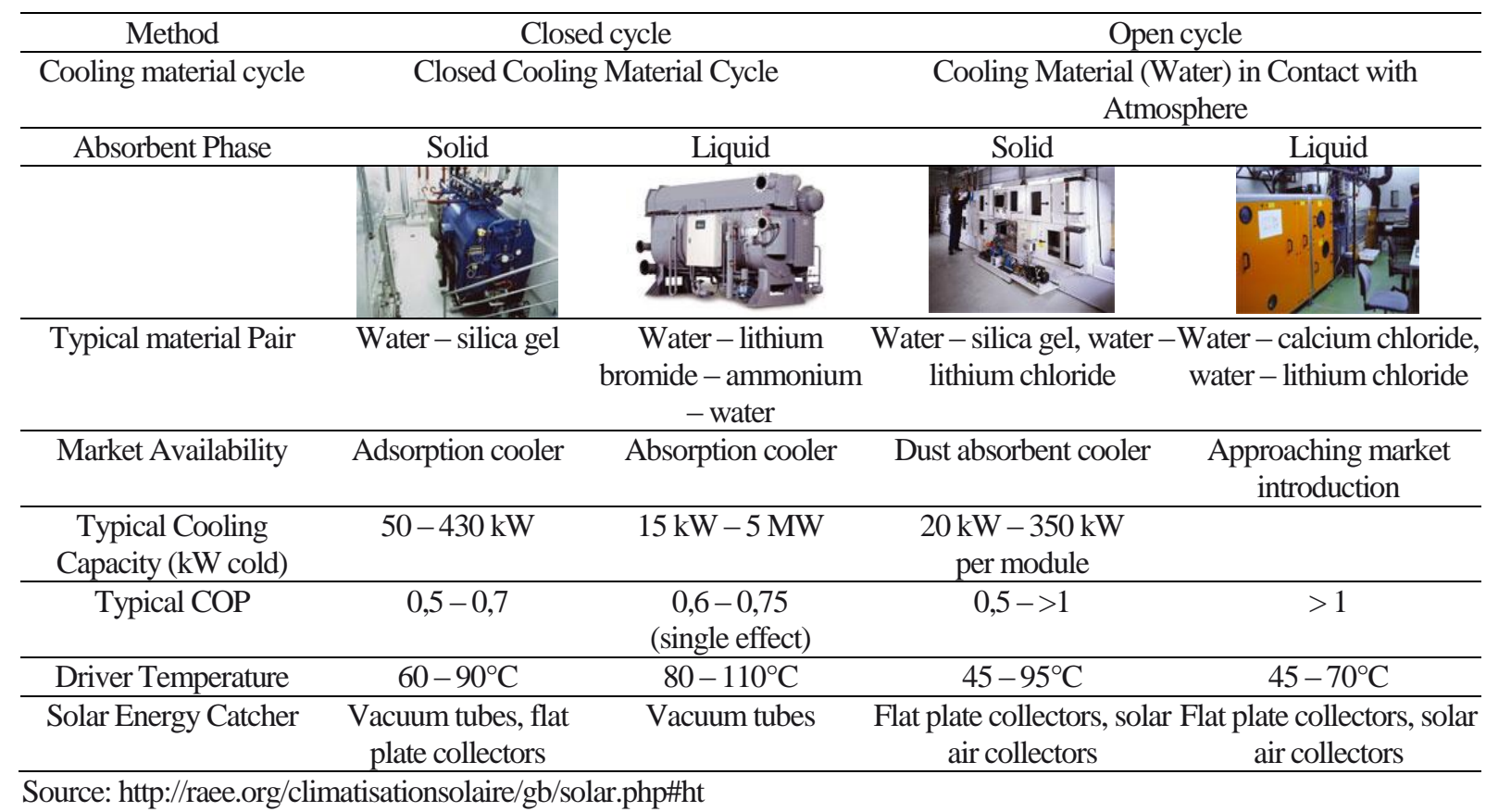

f. Does not create side effect in form of dangerous substance, like CFC and HCFC which is greenhouse gas.

g. Does not create noise because no parts inside element tools are moving.

h. System tools are in form of modular system, make them easy to install and can be adapted with space availability.

i. Easy tools handling and almost no operational cost needed (Reichardt, 2010).

j. This cooling system is a mature technology with high efficiency level and can be combined with photovoltaic system (Ullah et al., 2013).

Based on Sargon's presentation (2011), solar thermal cooling system has more efficiencies if compared with photovoltaic cooling systems that are described furthermore. The solar cooling efficiency in solar thermal cooling system is higher than photovoltaic cooling system, the rooftop area of solar thermal panels can be smaller than photovoltaic panels, the installation of solar thermal cooling system has a lower cost than photovoltaic system, and the energy payback time in solar thermal cooling system is faster than photovoltaic cooling system.

\section{Appropriately Applied Solar Thermal Cooling System on Building in Tropical Climate Area}

The use of solar thermal cooling system with open system is a promising potention on building with high humidity load and high air circulation level needs. Climate condition in Indonesia, with nearly constant temperature between inside space and outside space, makes circulation level is fairly low and contains high humidity, therefore is very appropriate if applying solar thermal cooling system with open cycle (IEA, 2012).

Installation of plumbing to stream and to restore air, as well as heat restore tools is really needed. In principle, this process can be combined with water cooling inside closed system (in example to move sensitive load from space through chilled ceiling) (Ullah et al., 2013).

\section{Adaptation of Solar Thermal Cooling System Application in Order to Make Energy Efficiency Can be Optimalized in Tropical Climate Area}

Das et al. (2012) designed experimental facilities to evaluate performance of cooling system using liquid as dust absorbent. This experimental study was done with system which used Lithium Chloride (LiCl) as dust absorbent solution. Study held in Delhi, India concluded their potential of solar thermal cooling system utilization using liquid driving force and dust absorbent at a time. Humidity reduction system which was also used in this system indirectly related with mass and heat exchanger, could eliminate possibility to dust absorbent liquid drips in to air supply flow.

Analysis about optimal design and performance from solar thermal cooler installation for housing building in tropical climate had already been done by 
Granjeon et al. (2013). Main goal from this research is to test system ability, which in this experiment used model from real absorbent cooler (produced and tested by INES), to operate in humid tropical climate. Using international standard which submitted by IEA, the model was tested in single family house with 200 $\mathrm{m}^{2}$ size consumed $60 \mathrm{kWh} / \mathrm{m} \mathrm{A}$, taking location in Darwin, Australia. Optimal design founded on constant comfortable condition, that is inside $26^{\circ} \mathrm{C}$ space temperature and $70 \%$ relative humidity. Parametric study showed that to obtain comfortable condition throughout the year, it needs minimum solar thermal energy chatcher with $20 \mathrm{~m}^{2}$ size and heat container tank with $0,6 \mathrm{~m}^{3}$ volume.

Experiment using two-stage air humidity reduction systems which contain membran unit and adsorption unit based on installed dust absorbent was analyzed at Solar Energy Research Institute of Singapore (SERIS) by Safizadeh et al., (2014). Goal from this research is to evaluate the performance of humidity reduction system from two-stage humidity reduction system in tropical climate condition and different operating parameter like air movement level and average air temperature. A numeric model constructed, there are evaporative cooled sorptive dehumidifier (ECOS) and membran unit inside MATLAB and then was tested with TRNSYS software to make two-stage humidity reduction system model. Result from this experiment showed that twostage system could decrease air humidity $8-10$ gram water per $1 \mathrm{~kg}$ dry air in warm and humid climate condition in Singapura.

Saman et al. (2007) did three researches about potencies of cooling system with dust absorbent using liquid in three cities, that is Bangkok (Thailand), Jakarta (Indonesia), and Singapore (Singapore). Cooling load characteristic from house floor area with relatively big size was analyzed, and based on this analysis, configuration from cooling system could be proposed to support optimal performance. Best configuration for dust absorbent system using liquid combined with conventional vapor compression system, potentially could decrease cooling load and electricity need which high enough in these three cities.

Boero (2012) did feasibility study evaluation technically from solar energy cooling system with absorbent, which was already built using numerical model available through dynamic modeling with TRNSYS equipment, for Guayaquil city, Ecuador with tropical climate. Solar energy cooling system with absorbent for Guayaquil condition has some components, that is emptying collector tube area with $24 \mathrm{~m}^{2}$ size, heat exchanger with $90 \%$ efficiency, one stage cooling absorbent liquid $\mathrm{LiBr} / \mathrm{H}_{2} \mathrm{O} 15 \mathrm{~kW}$, cooling tower $35 \mathrm{~kW}$, insulated cold container tank with $3 \mathrm{~m}^{3}$ volume, fan coil unit $10 \mathrm{~kW}$, five pumps, and three control tools.

Result from simulated model which was proposed to Guayaquil city showed that these system could provide cooling needs to office building with $164 \mathrm{~m}^{3}$ volume for the hottest season in a year. Application with simplified control strategy, although has limitation at some parts when far inlet parameter outside estimated operational system, is a very good achievement from size aspect and solar energy cooling system examination, where highly dependent to some factors which cannot be evaluated when applying fixed position method.

Reichardt (2010) did an experimental project at Guaratinguetá, Brazil and produced the right and effective solar thermal cooling technology from cost aspect and applicable, in form of closed cold water cycle which integrated with one stage $\mathrm{LiBr}-\mathrm{H}_{2} \mathrm{O}$ absorbent cooler and cooling tower, solar thermal collector equipment in form of flat-plate collector which has the best performance from cost aspect, and a reserve system in form of conventional compression driver with electricity energy on separated air conditioning system which is still used because heating water with gas can move one stage cooler and thus can cause operational cost becomes six times higher. The results done by previous researchers are summarized in Table 3.

Some researchers use different methods in deciding optimal design in the right application of solar thermal cooling system to area with humid tropical climate, among others are using numerical model and simulated method with certain program, or using real model which can be directly applied to various functions of building. These researchers had applied solar thermal cooling system and dust absorbent in the same time and reduce humidity on some different areas which has humid tropical climate, thus proving that this is the right system to be used for these area.

\section{CONCLUSIONS}

The right solar thermal cooling system to be applied on building in Indonesia, with its tropical climate and contain high air humidity, is open cycled solar thermal cooling systems. This system can decrease air humidity and adapt with space thermal comfortability. From forementioned research, system that can be proposed in order to get optimal energy efficiency is dust absorbent cooler system using humidity reduction machine which is operated with absorbent in form of liquid. 
Table 3. Research Results about Solar Thermal Cooling System in Tropical Cimate Area

\begin{tabular}{|c|c|c|c|}
\hline Name, Year & Research Location & Method & Result \\
\hline Das, et al., (2012) & Delhi, India & Experiment & $\begin{array}{l}\text { The potential use of solar energy cooling system } \\
\text { using liquid driving force and dust absorbent at } \\
\text { the same time }\end{array}$ \\
\hline $\begin{array}{l}\text { Granjeon, et al., } \\
\text { (2013) }\end{array}$ & Darwin, Australia & $\begin{array}{l}\text { Experiment using model from } \\
\text { real absorbent cooler }\end{array}$ & $\begin{array}{l}\text { Optimal design needed at least solar thermal } \\
\text { collector with } 20 \mathrm{~m}^{2} \text { size and thermal storage } \\
\text { tank with } 0,6 \mathrm{~m}^{3} \text { volume }\end{array}$ \\
\hline $\begin{array}{l}\text { Safizadeh, et al., } \\
\text { (2014) }\end{array}$ & Singapura, Singapore & $\begin{array}{l}\text { Numerical model, that is } \\
\text { evaporative cooled sorptive } \\
\text { dehumidifier (ECOS) and } \\
\text { membran unit inside } \\
\text { MATLAB }\end{array}$ & $\begin{array}{l}\text { Two-stage system can reduce air humidity } 8- \\
10 \text { gram water per } 1 \mathrm{~kg} \text { dry air in warm and } \\
\text { humid climate condition }\end{array}$ \\
\hline $\begin{array}{l}\text { Saman, et al., } \\
\text { (2007) }\end{array}$ & $\begin{array}{l}\text { Bangkok (Thailand), } \\
\text { Jakarta (Indonesia), } \\
\text { Singapura (Singapore) }\end{array}$ & $\begin{array}{l}\text { Experiment with house model } \\
\text { which has relatively big size }\end{array}$ & $\begin{array}{l}\text { Best configuration to dust absorbent system with } \\
\text { liquid is combined with conventional vapor } \\
\text { compression system }\end{array}$ \\
\hline $\begin{array}{l}\text { Boero, Andrea } \\
(2012)\end{array}$ & Guayaquil, Ecuador & $\begin{array}{l}\text { Feasibility study using } \\
\text { available numerical model } \\
\text { through dynamic modelling } \\
\text { with TRNSYS tool }\end{array}$ & $\begin{array}{l}\text { Solar thermal cooling system with absorbent } \\
\text { - Emptying collector tube area } 24 \mathrm{~m}^{2} \text {, } \\
\text { - Heat exchanger with } 90 \% \text { efficiency, } \\
\text { - One stage } \mathrm{LiBr} / \mathrm{H} 2 \mathrm{O} \text { absorbent cooling } \\
\text { liquid } 15 \mathrm{~kW} \text {, } \\
\text { - Cooling tower } 35 \mathrm{~kW}, \\
\text { - Insulated cold container tank } 3 \mathrm{~m}^{3} \text {, } \\
\text { - fan coil unit } 10 \mathrm{~kW} \text {, } \\
\text { - } 5 \text { pumps, } 3 \text { control tools }\end{array}$ \\
\hline Reichardt (2010) & Guaratinguetá, Brazil & Experimental project & $\begin{array}{l}\text { Right and effective solar thermal cooling } \\
\text { technology from cost aspect } \\
\text { - Closed cold water system with one stage } \\
\text { LiBr-H2O absorbent cooler and cooling } \\
\text { tower, } \\
\text { - Solar thermal collector use equipment flat- } \\
\text { plate collector } \\
\text { - Reserve system: conventional compression } \\
\text { driver with electricity energy }\end{array}$ \\
\hline
\end{tabular}

Source: Researcher Analysis

Eventhough have big advantage, solar thermal cooling system is still constrained with presence of some weaknesses, for example, the tools can only be obtained with relatively expensive price, and its installation is costly. This matter certainly becomes obstacle to small scale building which wants to use this system because the efficiency from economic aspect reduced. This constraint become challenge to us to create equipment system innovation with lower cost to make this more applicable for larger society.

In addition to that, there are still other obstacles and weaknesses in solar thermal cooling system application on building in Indonesia that still need to overcome and need further investigation, which are the followings:

a. Low energy density and have not been applied yet in long term.

b. User scale limitation.

c. Does not create electricity energy, or in the other words, only produces small scale energy. d. Additional energy source or additional energy container tank is needed to lower solar light condition in long term.

e. Opinion from some people that this system equipment is not visually attractive.

f. Production process for this system equipment can produce pollution.

g. System equipment installation experts are not available yet in many area which need them.

h. Over heat produced from solar energy catching process is unsaleable.

i. Optimization of cooling system is highly dependent to location and building orientation.

\section{REFERENCES}

Boero, A. (2012). Modelling and Simulation of a Solar Powered Absorption Cooling System in a Tropical Climate City for Small-Scale Application. Dissertation Master of Science, Energy 
Conversion and Management University of Nottingham.

Das, R.S. et al. (2012). Investigations on Solar Energy Driven Liquid Desiccant Cooling Systems for Tropical Climates. In Proceedings of the $50^{\text {th }}$ Annual Conference, Australian Solar Energy Society (Australian Solar Council). Melbourne.

European Solar Thermal Industry Federation. (2014). Cooling with Solar Thermal, [Online], accessed in http://www.estif.org/st_energy/technology/ solar_thermal_cooling_and_air_conditioning/ [Juni $\left.12^{\text {th }}, 201 \overline{4}\right]$.

Granjeon, R. et al. (2013). Simulation as a Design Tool for Solar Cooling Systems in Humid, Tropical Climates. In Proceedings of BS2013: $13^{\text {th }}$ Conference of International Building Performance Simulation Association. Chambéry, France.

Ishaya, S. (2011). Solar Cooling Methods and Applications.

International Energy Agency Renewable Energy Division. (2012). Technology Roadmap Solar Heating and Cooling. Paris, France.

Lim C. H. (2009). An Overview of Solar Assisted Air-Conditioning System Application in Small Office Buildings in Malaysia. In Proceedings of the 4th IASME/WSEAS International Conference on Energy and Environment.

Marc, O. et al. (2012). Decision Making Tool to Design Solar Cooling System Coupled with Building under Tropical Climate. Energy and Buildings, 49, pp. 28-36.

Mittal, V. et al. (2008). The Study of Solar Absorption Air-Conditioning Systems. Journal of Energy in Southern Africa, 16(4).

Parmar, H. \& Hindoliya, D.A. (2011). Desiccant Cooling System for Thermal Comfort: A Review.
International Journal of Engineering Science and Technology (IJEST), 3(5).

Reichardt, T.F. (2010). Technical and Economic Assessment of Medium Sized Solar-Assisted AirConditioning in Brazil. Dissertation degree of Mestre Urban and Environmental Engineering, Departamento de Engenharia Civil do Centro Técnico Científico da PUC-Rio, Rio de Janeiro.

Safizadeh, M. R. et al. (2014). Two-Stage AirDehumidification System for the Tropics Experimental and Theoretical Analysis of a Lab System. In SHC 2013, International Conference on Solar Heating and Cooling for Buildings and Industry. Freiburg, Germany, September 23-25 2013, Energy Procedia, 48, pp. 982-990.

Saman, W. et al. (2007). Residential Application of Solar Liquid Desiccant Cooling System in Tropical Countries of South East Asia. In Proceedings 2. International Conference Solar Air-Conditioning. Tarragona (ES), October 18 19.

Singhal, AK. (2014). Status and Scope of Solar Cooling in India. In Sun Focus Issue 4 April-June 2014.

Ullah, K.R. et al. (2013). A Review of Solar Thermal Refrigeration and Cooling Methods. Renewable and Sustainable Energy Reviews, 24, pp. 499513.

University of Maryland Solar Decathlon Team. (2007). Liquid Desiccant Waterfall, [Online], accessed in http://2007.solarteam.org/page.php? $\mathrm{id}=641$ [January $\left.13^{\text {th }}, 2016\right]$.

Wang, R.Z. et al. (2009). Solar Sorption Cooling Systems for Residential Applications: Options and Guidelines. International Journal of Refrigeration, 32, pp. 638-660. 